\title{
The Impact of Introducing in High-tech Multinational Companies on Local Economy and Culture
}

\author{
${ }^{1}$ FANG Youxia, ${ }^{2}$ Shi Yeli \\ ${ }^{1}$ Zhejiang Ocean University, Zhoushan, China \\ ${ }^{2}$ Associate Professor of Foreign Language College, Zhejiang Ocean University, China
}

\begin{abstract}
Recent years, high-tech multinational companies continue to seek resources and expand the market in China. Meanwhile they also bring high-tech technology to China, which helps China with its regional technological innovation and industrial upgrading. This paper analyzes the pros and cons of introducing wellknown high-tech multinational enterprises to China's regional economy and culture. In view of the present situation, it points out that it is necessary to fully stimulate the effect of the high-tech industry on the regional economy, and to improve the learning and absorptive capacity of the local enterprises. Some constructive suggestions are put forward on how the government should support the regional industrial transformation and upgrading and how to deal with cross-culture conflicts between MNC and the local.
\end{abstract}

Keywords: High-tech, multinational companies, regional economy and culture.

\section{INTRODUCTION}

With the development of knowledge-based economy and the international division of labor, high-tech multinational companies search for the best allocation of resources to organize production globally. China is still the "world factory" favored by high-tech multinational companies. However, nowadays China has a dual identity. It is more popular with its great potential as an emerging market, which attracts Airbus and Boeing and many other high-tech multinational companies to invest in China. But the introduction of high-tech multinational companies, for China, is destined to be both opportunities and challenges. In recent years, Chinese local governments have also paid more and more attention to the development of high-tech industries. Many provinces and cities have rolled out a series of policies for high-tech industry development.

Zhan Boming (2004) pointed out that the development trend of multinational companies in China for the production and research is localizing gradually. They moved the manufacture of some parts of their products to China and formed a complete production chain with their domestic production.[1]

This seems a win-win strategy as it helps multinational companies gain the best resources allocation to further decrease cost also helps the Chinese regional industrial upgrading.

\section{CaSes of CurRent High-TeCh Aviation Industries}

\subsection{Tianjin Aviation Economic Zone}

In 2006, Airbus set up the A320 assembly line in Tianjin, which has delivered more than 200, and the market share has increased significantly. In 2015, Tianjin Aviation Economic Zone achieved output value of 71.7 billion yuan, which has increased by more than $40 \%$. Airbus industry has experienced more than one decade's development and become the pillar of Tianjin economy. The aviation industry with its sophisticated technology has been regarded as the apex of the manufacturing industry, and dubbed as the "industrial flower."

This industry, featured by extremely high-tech intensity, has provided Tianjin and even the whole country with the opportunities to learn from its technology spillover effect and ecological formation.

At the beginning of 2016, an important project for Sino-French cooperation between Airbus and Tianjin started smoothly aimed at constructing a center for completion and delivery of A330 widebody aircraft. French leaders attached great importance to Airbus Tianjin project, and were willing to form a substantial enduring industrial partnership with China. Airbus chose China to place the first 
outside assembly line, which indicated that the relationship with China was prioritized. France also decided to enhance cooperation with Tianjin Civil Aviation University in order to promote bilateral friendly relations.

Airbus employees from China also have to be trained to be qualified in accordance with the company's standards. At Airbus, the company provides nearly ten training programs for Chinese employees, including professional skills, pre-job training, technical training, leadership training and English training. Even the pre-job training had to take one and a half years. After training, those Chinese employees would be the backbone of the aviation field. The Airbus project not only created large number of job opportunities for China but also provided professional training.

At present, the project is progressing rapidly, and is expected to be completed in August 2017. By then, Tianjin will be the world's fourth city producing single-channel and dual-channel aircraft at the same time. It will further improve the Tianjin's aviation industry chain, and promote the development of China's aviation industry. Driven by the Airbus project, Tianjin's aviation industry has formed an industrial agglomeration. More than 60 well-known domestic and foreign aviation manufacturing companies and more than 120 aviation service companies have settled in Tianjin. Also, more than 20 major projects are under way.

The introducing of Airbus in Tianjing Binhai New Area has a significant impact on the local economy.

\subsection{Zhoushan Boeing 737 Completion and Delivery Center}

The world's leading aircraft manufacturer Boeing's first overseas plant settled in Zhoushan, Zhejiang Province. The 100-year-old Boeing company has finally taken the first step in overseas production operations. Boeing 737 Zhoushan Center consists of two parts, namely Boeing and China Commercial Aviation 737 aircraft completion center, and Boeing-owned 737 delivery center. Boeing 737 completion and delivery center project settled in the Zhoushan Archipelago New Area, a major cooperation project in the field of civil aviation between China and the United States. According to the survey, at present, one fourth of more than 40 Boeing737 airplanes off the Seattle assemble line are delivered to Chinese customers every month. That also verifies that China is a large market coveted by high-tech multinational companies across the world. In the past five to ten years Zhejiang province also has been engaged in transformation and innovation, A number of companies are involved in striving for the high-end market. Zhejiang aviation industrial cluster is already in embryo and is expected to rise rapidly.

\section{THE IMPACT OF High-TECH MULTINATIONAL COMPANIES ON LOCAL ECONOMY}

From the above examples of two high-tech companies and regional cooperation, it can be clearly seen the positive impact of aviation industry on economic growth, which is mainly showed through the following aspects:

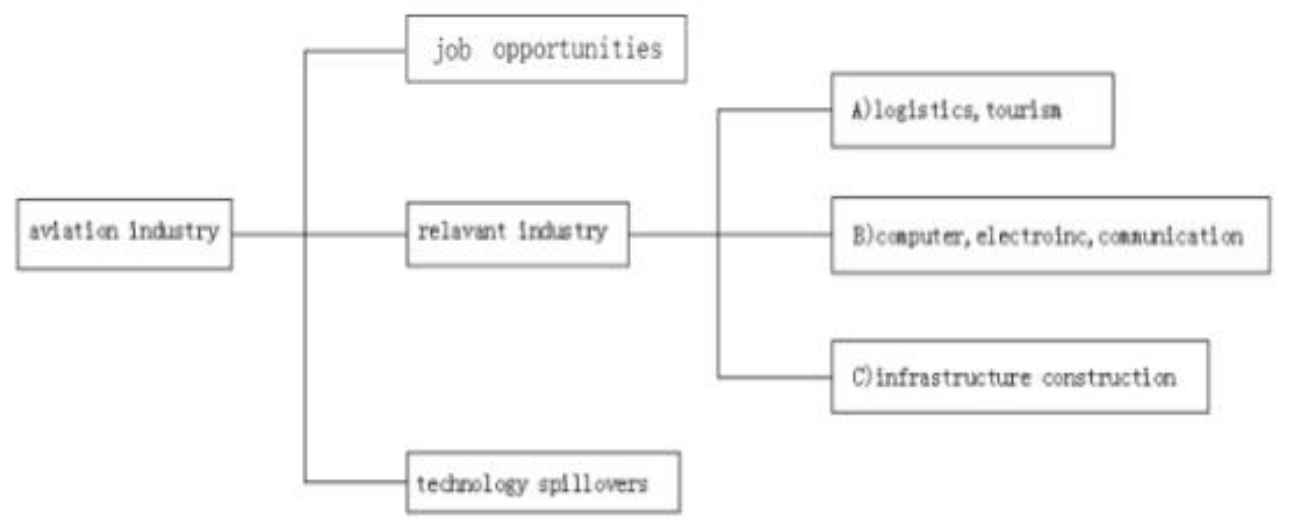

1) A Substantial increase in job opportunities and improve the quality of labor force. As planned, once Zhoushan Boeing factory achieves full capacity, it can deliver 100 aircraft a year, and will create 2,000 jobs. Zhoushan's University graduates will also have more and more opportunities to stay and work in Zhoushan. This will not only alleviate regional employment issues, but also bring in high-tech talents and high-quality labor force for this region. Moreover it will also give local companies a strong boost in innovating and upgrading industrial structure. 
2) Promote Related Industries and Build a New Competitive Advantage

a. Large aircraft manufacturing industry will inevitably lead to the development of local logistics and transport industry. The rapid development of technology has made the logistics industry develop rapidly.[2] COSCO Logistics is a typical example of seizing the opportunities. After Airbus settled in Tianjin, COSCO Logistics boarded the platform to compete with the international top logistic companies. Opportunity also means challenge. COSCO stood out from a number of logistics companies, and successfully won the Airbus project. After having won the project it further expanded the carrying capacity of the Tianjin Port. It was obviously that the Airbus A320 project for COSCO and Tianjin both are win-win situation. COSCO was promoting their own team, also won the recognition of the world counterparts. What Airbus A320 projects brought to $\mathrm{COSCO}$ is not only a world-class contract orders, but also the experience in international competition. COSCO Logistics's has set a good example for local logistics companies who were eager to cooperate with high-tech industries. Now Tianjin has formed an integrated transport network of land, sea and air which gradually serves as a functional framework system for Chinese northern regions and the Northeast Asian countries, such as Japan and South Korea, offering warehousing, processing, transportation, information, and other services. The series of production essentials require the improvement in infrastructure suitable for Airbus A320 material transport, such as harbors, highways, railways, airports, etc. especially large aircraft parts transport requirements such as port lifting facilities and transport channel. Thus promoting the development of the logistics, and improving the efficiency of the logistics industry. At the same time, the development of high-efficiency air transport industry will also promote the tourism industry. As a transport-convenient city, the resorts around can be more attractive.

b. To support a large aircraft manufacturing industry there must be some relevant industries like the computer industry, electronic communications, mechanical equipment and metallurgy. Tianjin Binhai New Area has cultivated the six leading industries of electronic communication, oil exploitation and marine chemical industry, modern metallurgy, machinery manufacturing, and food processing. And its IT manufacturing is in the leading position of the country. In 2004, the industrial output reached 115 billion Yuan, accounting for more than $40 \%$ proportion of the new industrial output value. Obviously, the high-tech aviation industry has also led to the development of those industries that support it. [3]

c. The aviation industry itself and its related industries will further improve the regional infrastructure construction. Airbus' settlement not only facilitated economic growth and promoted the rapid development of the associated industries in Tianjin but also largely improved infrastructure, such as railways, port terminals, roads, pipelines and other modern integrated transport system. The Tianjing economy started a new round of rapid development.

Similarly, the settlement of the Boeing 737 factory will also further contribute to the infrastructure construction of Zhoushan. Zhoushan Aviation Industrial Park is located on the Zhujiajian Island, Putuo District. The planning area is about 7.88 square kilometers. It is divided into flight service area, comprehensive supporting area, manufacturing area, assemble maintenance area and ecological landscape area. It is estimated that the total investment of the park is 10 billion yuan. Such a large project means that in the future there will be a large number of Boeing company's expatriates and their families living in Zhoushan. Zhoushan hospital has prepared for the international health care center for foreigners and domestic high-end consumers. An International school will soon be completed and put in use.

3) High-tech technology spillovers promotes the development of high-tech industries in the region. For a long run, Zhejiang Province has been seeking for the way to continue its transformation, innovation and development. So the aviation industry should be given a priority for those Zhejiang companies who were intended to transform to high-tech companies. A number of companies began to enter into the high-end market in order to accommodate the needs of industrial upgrading. Nowadays we can see in Zhejiang province that from the Western Airline to other private companies to participate in large aircraft manufacturing. A new force in the aviation industry is emerging in Zhejiang. It is believed that the settlement of Zhoushan Boeing factory at this right time is a catalyst for the development of Zhejiang aviation industry. And technology spillovers provide opportunities for those regional companies in cooperation with the Boeing factory. 
From those impacts listed above it can be clearly concluded that the large-scale civil aviation industry directly or indirectly affected the development of other industries in the region, enhancing the local economic growth.

\section{The Negative ImPACT ON REgional ECONOMY}

The introduction of well-known multinational companies can be a double-edged sword. To some extent, it is certainly a win-win strategy, especially injecting a driving force of innovation for China which is right in the transition period of innovation. And it has a better impact on China's regional infrastructure construction, industrial structure transformation and upgrading. However, the reality cannot be ignored that the majority of these well-known high-tech multinationals who invest in developing countries such as China are aimed to transfer the low technological sector to developing countries where labor costs are relatively low compared with their own countries and also to explore the potential market by relocating the last part of production which often demands more labor. This is extremely cost-effective. In other words, these large multinational companies so far still choose to place the least valuable part of "smile curve" in China. An Aviation expert Qi Qi said that we need to view the landing of Boeing Zhoushan Center rationally. First of all, this year in Zhoushan Boeing set up the completion and delivery center, but it is completely different with Airbus in Tianjin before.

Completion and delivery means that the aircraft is almost finished and then delivered to China, only left for painting and final testing. The lower technical requirements and involvement of less related industries lead to weak impact on the local economy. What's more, compared with Europe, the United States sets more obstacles on the technical barriers.

On the other hand, China is currently facing a serious form of transformation. China's self-dependent innovation and industrial transformation and upgrading will be more difficult than ever before because China has been labeled as lacking of independent innovation capability. Moreover, under the globalization of science and technology, the emergence of technology will soon be replaced by new inventions. However only high-tech multinational companies will continue to dominate the global market for they have mastered the high-end technology, capital and sales network, the three key factors of global production structure. Consequently, the developing country's original domestic market service production structure gradually, unequally and apparently irresistibly is replaced by a production structure that is primarily adapted to serve the global market.[4] In the technical aspects high-tech multinational companies are almost in a monopoly position. The introduction of high-tech multinational companies will make regional high-tech companies hard to enter the technology market as its barriers will be much higher than before and the advantage of the technology market space is getting smaller. There are challenges of introducing high-tech multinationals. How to deal with such kinds of challenges has already become a great concern.

\section{Ways to Deal With Challenges}

Sanjaya Lall(1983) held the view that the technology characteristics of developing countries are of small scale standard and labor-intensive, but the formation of this technology contains the enterprise's internal innovation activities. That means that the developing countries can cultivate their own "unique advantages" by internal innovation.[5]

A developing country such as China, which started its modernization drive in 1949, potentially has the advantage of backwards in its pursuit of technological innovation and structural transformation.[6] Those technology advanced countries are pioneers in the industrial innovation field, which absolutely calls for costly and risky investments in research and development. By contrast, those comparatively backward countries can learn from the experiences that the developed countries had paid for. Latecomers can easily tap those resources and combine with their own situation to forge unique advantages.

China, as a developing country, is on the verge of technological innovation. The competition in the international commodity market is becoming more and more intensive, and only a few companies with unique core technology can develop technology-intensive products and export some high-tech products to get the benefits in this battlefield. Therefore, only by giving a full play to the role of hightech industries on the regional economy, and improving learning and absorption capability can regional enterprises gain a firm foothold in the market. In addition, they should develop further cooperative relations with high-tech multinational companies and make full use of the advantages that 
they brought. Normally those high-tech companies will invest a large amount of money in industrial upgrading, infrastructure constructing and high-tech innovative talents cultivating. Another favorable condition is that Chinese national condition is different from others. Governmental policies play an important role in the Chinese economy. Thus, regional enterprises can utilize the favorable policies toward the high-tech industry so as to upgrade the industrial structure as soon as possible and improve the ability of self-dependent innovation.

How to absorb foreign capital and make it the basis for improving the international competitiveness of the country is a common problem faced by developing countries. The Chinese government should increase financial input on scientific research, vigorously support and guide the development of innovative enterprises.

Moreover, emphasis should be put on cultivation of talents of innovative technology in colleges and universities, for the technological innovation is source of power for the whole nation to make a big progress.

\section{ImPaCt ON Local Culture}

The introduction of high-tech multinational companies has led in such an environment where employees of different culture backgrounds work together. Take Microsoft China as an example, it is very common to see that five of the eight in one team are of five different culture background, as they may come from China, France, Japan, Italy or India. The leaders of such a group have to understand the differences between each member's cultures and know how to deal with their behaviors and attitudes. However, in reality, things are not easy as we expected.

Stephen P. Robbins and Mary Coulter put forward an academic term named monolingualism in the book of Management. Monolingualism is one sign that a nation suffers from parochialism - viewing the world sorely through one's own eyes.[7] People who suffer from parochialism cannot realize that different people have different ways to live and work. They just simply admire their own values and customs which can be described as "ours is better than theirs".

Those high-tech multinational companies tend to suffer from a process of monolingualism. As most of expatriates might look down upon a developing countries' technology level or doubt about the professionalism of local talents.

Similarly, as a country with long history, before those high-tech multinational companies coming to China, Chinese regional culture was full of monolingualism and had the tendency to exclude "outsiders". People mostly thought that their own values culture and customs were the best and had basked in self-complacency. It would easily lead to conflicts and crises for a newly arrived multinational company to develop or to have local talents to work with.

However after those high-tech multinational company making inroads into their turf, they began to realize the huge gap between themselves and those multinational companies, especially in the aspects of advanced technology and corporate culture. Then the situation was totally reversed. Local talents began to regard working in a high-tech multinational company as a huge proud to boast to their peers as their salary and bonus might be much higher and their working environment could probably be better. Also they feel triumphant to show off that they were able to work with different kinds of people under different culture backgrounds. Another thing is that a multinational company's culture is mostly defined by those top executives. In reality employees tend to emulate their boss' behavior and think that will satisfy their boss.

Thus, those employees working in local multinational companies could be easily influenced by their corporate culture which originates from another culture. And with the increasing number of multinational companies in China, the interaction between Chinese region and multinational companies has become more and more frequent the mutual penetrations or integration of cultures are unavoidably taking place.

In Zhoushan, the place where the Boeing factory and other high-tech multinational companies just settled down, was becoming more international. Citizens pay more attention to the children's education especially in English, science. In addition, in order to keep in line with more and more multinational companies, Zhoushan adult English training institutions are expanding gradually to help local talents working smoothly in those international companies. Local people also start to advocate 
science and technology. Young children are proud of being admitted by international schools and high school students are encouraged to study abroad. Some even try to imitate the foreign lifestyle and regard doing what the foreigners do as a trendy thing. This kind of blind worship may lead to the loss of own culture identity.

\section{THE WAY TO DEAL WITH CULTURE IMPACT}

Certainly there are many things to learn from those high-tech companies and employees are also required to orient themselves to the values, beliefs, and customs observed by their company's culture and to respect their colleagues from different culture backgrounds. High-tech multinational companies can influence local culture, but they can be influenced by local culture as well. To realize their localization strategy, they have to integrate with local culture consciously. That is to say, intercultural acculturation is mutual. There is no need for local people to worship everything from foreign countries, for they are in an equal and cooperative relationship. Respect for one another's culture is fundamental for companies to go further. Only by integrating rather than monopolizing can culture play its part in the company development.

\section{Conclusion}

China has undergone dramatic economic development since the policy of reform and opening up. In the past 40 years, many world-famous high-tech companies, such as Ford and General Motors from the US, Sony and Toyota from Japan, Sumsung and Hyundi from South Korea, have invested in China, which had great impact on Chinese regional economy and culture. Though introducing in hightech multinational companies is a double-edged sword, it is an inevitable trend of globalization. Thus, it is a wiser choice to take positive measures to cope with the accompanying problems, such as the technological monopoly that may take up positions in regional markets, and culture shock or culture output and information monopolization.

In the economic aspect, it is suggested that developing countries should possess their own unique advantage as an attraction to foreign investments, enhance cooperative relations with high-tech multinational companies and make full use of the advantages that they brought in.

In the cultural aspect, it is more urgent than ever for developing countries to cultivate intercultural awareness and be ready to learn and accommodate other cultures. And that is also an essential qualification demanded on an employee who is working in a multinational company. For regional people, there is no need to worship everything from foreign countries, for their relationship is on an equal and cooperative basis. It is more wisely to select the essence, and abandon its dross in dealing with the impact of foreign cultures. Only in this way, can the mutual benefits be maximized and a harmonious and win-win scenario be forged.

At present, the amazingly rapid development of technology in areas of transportation and social media has brought about the economic globalization in a fast way. With more and more high-tech multinational companies coming into China, it is urgent to be aware of the impacts of economy and culture those companies may produce on their destinations.

\section{REFERENCES}

[1] Zhan B., MNCS' Expanding Trend, Influence in China and Our Countermeasures. Wuhan University Journal(Humanity Sciences),Vol.57.No.4, Pp 448- 453, (2004).

[2] Liang A., Wang Q., The Economy Impact and Linkage of Airbus Project on Tianjin Binhai New Area's. The Science Education Article Collects, P 216, (2008).

[3] Wang C., Tan Y., Zhao L. Analysis of regional economic effect of A320 settling in Tianjin. Journal of Xidian University, (Social Sciences), Vol.16 No.6, Pp 13-16, (2006).

[4] Susan S., States and markets. Yang Guangyu, translation. Second edition. Shanghai: People's Publishing House,(2006).

[5] Wei S., Review:Transnational Co.Theory of Developing Countries. Journal of Zhengzhou Institute of Aeronautical .Industry Management.Vol.18No.4, Pp 13-16, (2000).

[6] Justin Y., Perspectives on Chinese Economic Growth. Academic Press, The Econometric Society World Congress in Shanghai, (2010)

[7] Stephen P.R., Mary C., Management. Tsinghua University press, (2013). 


\section{AUTHORS' BIOGRAPHY}

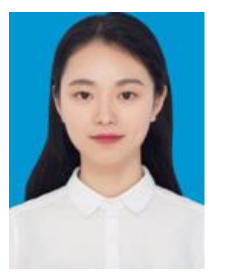

Fang Youxia, born in 1995, Chinese. She is a junior of Foreign Language College, Zhejiang Ocean University, majoring in business English.

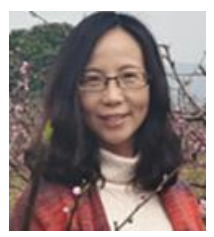

Shi Yeli, Associate Professor of Foreign Language College, Zhejiang Ocean University, China. Master of Arts in Literature and Language, Zhejiang University. Research area: cross-culture communication, metaphor, and business English teaching. 